\title{
Spermatophyte Flora of Liangzi Lake Wetland Nature Reserve
}

\author{
Xinyang Zhang, Shijing He", Rong Tao, and Huan Dai \\ Wuhan Institute of Design and Sciences, Wuhan 430205, China
}

\begin{abstract}
Based on route and sample-plot survey, plant resources of Liangzi Lake Wetland Nature Reserve were investigated. The result showed that there were 503 species of spermatophyte belonging to 296 genera of 86 families. There were 5 species under national first and second level protection. The dominant families of spermatophyte contained 20 species and above. The dominant genera of spermatophyte contained 4 species and below. The 86 families of spermatophyte can be divided into 7 distribution types and 4 variants. Tropic distribution type was dominant, accounting for $70.83 \%$ in total (excluding cosmopolitans). The 296 genera of spermatophyte can be divided into 14 distribution types and 9 variants. Temperate elements were a little more than tropical elements, accounting for $50.84 \%$ and $49.16 \%$ in total (excluding cosmopolitans) respectively. Reserve had 3 Chinese endemic genera, reflecting certain ancient and relict. The purpose of the research is to provide background information and scientific basis for the protection, construction, management and rational utilization of plant resources in the reserve.
\end{abstract}

\section{Preface}

Flora refers to the sum of all plant species in a certain region or country. It is the result of the development and evolution of the plant kingdom under certain natural and geographical conditions, especially under the comprehensive effect of natural and historical conditions. With the development of Botany, the researches of flora have been carried out continuously. The basic characteristics and division framework of Chinese flora have been basically completed in the efforts of several generations of botanists. New distribution information can be obtained through systematic and in-depth floristic investigation and collection. For example, some plants have been extinct in the origin, but may be found in other regions. As a great biodiversity country, China has accumulated rich data on the basic characteristics, division and resources of flora. This provides an important theoretical basis and practical guidance for biodiversity conservation [1].

\section{Research area and method}

\subsection{General situation of research area}

Liangzi Lake Wetland Nature Reserve is located in the southeast of Hubei Province, on the south bank of the middle reaches of the Yangtze River. It borders Daye in the east, Xianning in the south and Jiangxia in the west. It is located between $114^{\circ} 31^{\prime} 19^{\prime \prime} \sim 114^{\circ} 42^{\prime} 52^{\prime \prime} \mathrm{E}$ and $30^{\circ} 04^{\prime} 55^{\prime \prime} \sim 30^{\circ} 20^{\prime} 26^{\prime \prime} \mathrm{N}$. The total area is 37946.3 hectares, including 31000 hectares of water area.

The Reserve belongs to subtropical monsoon climate area, with obvious monsoon climate. The annual average temperature is $17^{\circ} \mathrm{C}$, the annual average rainfall is $1663 \mathrm{~mm}$, the average sunshine hour is 2061 hours, and the frost free period is 270 days. The rain bearing area is 208500 hectares, and the annual average water level is $17.81 \mathrm{~m}$. The lowest water level is $16.69 \mathrm{~m}$ in March and the highest is $18.78 \mathrm{~m}$ in August. The soil can be divided into four types and 11 sub types: red soil, purple soil, tidal soil and paddy soil. Among them, there are 3 soil types and 6 subclasses in dry land soil, 1 soil type and 5 subclasses in paddy soil [2-3].

\subsection{Field investigation method}

The plant resources of Liangzi Lake Wetland Nature Reserve were investigated by using the methods of route and sample-plot. The survey sites were Wangdian, Chenmujiang, Liujiabao, Xinguohuang, Zhongxiaowan, Zhangjiacun, Banzuidiu, Dashanchen, Xiabianwan, Hetouzui, Zhoujiaqiao, Laowuxia, Dongbianfang, Xiajiacun, Dazuiwan, Daluhu, Xiaojiazui, Dingluo, Caiyucun, Dawenzui, Qiaotouxu, Xiaoxu, Dajiang, Kuangshuai, Xiamincun, etc.

For areas with rich vegetation diversity, the route survey method was mainly used. The ecological sampleplot method was used to investigate the community in the area with less vegetation damage. Recorded the name of the plant, collected the plant samples, and taken photos [4]. After the field survey, the collected plant specimens were sorted out and identified by referring to Flora of China, Atlas of Higher Plants of China and Flora of Hubei. Combined with the relevant literature, the list of plants in the reserve was finally determined, and the floras of spermatophyte in the reserve were analyzed.

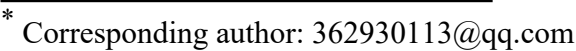




\section{Results and analysis}

\subsection{Basic composition}

There were 503 species of spermatophyte in Liangzi Lake Wetland Nature Reserve belonging to 296 genera and 86 families. Among them, there were 354 species of dicotyledons in 69 families and 213 genera, 149 species of monocotyledons in 17 families and 83 genera (Table 1). Dicotyledons accounted for $80.23 \%, 71.96 \%$ and $70.38 \%$ of the total families, genera and species in reserve, while monocotyledons accounted for $19.77 \%$, $28.04 \%$ and $29.62 \%$ of the total families, genera and species in reserve. Among them, herbs accounted for a large proportion of dicotyledons, shrubs and arbors were relatively scarce, and wetland plants were more in monocotyledons.

Table 1. Species composition of spermatophyte in Liangzi Lake Wetland Nature Reserve

\begin{tabular}{lccc}
\hline \multicolumn{1}{c}{ Item } & $\begin{array}{c}\text { Monocotyledonous } \\
\text { plant }\end{array}$ & $\begin{array}{c}\text { Dicotyledonous } \\
\text { plant }\end{array}$ & Total \\
\hline Number of families & 17 & 69 & 86 \\
Number of genera & 83 & 213 & 296 \\
Number of species & 149 & 354 & 503 \\
\hline
\end{tabular}

\subsection{Composition of families}

There were 86 families of spermatophyte in Liangzi Lake Wetland Nature Reserve. According to the number of species in the family, they were divided into five grades (Table 2): large family (more than 50 species), larger family (20-49 species), medium family (10-19 species), oligarchic family (2-9 species) and single family (1 species).

According to the statistical results, there were 2 families in the large family, accounting for $2.32 \%$ of the total families in reserve, including 121 species, accounting for $24.06 \%$ of the total species in reserve. There were 3 families in the larger family, accounting for $3.49 \%$ of the total families in reserve, including 92 species, accounting for $18.29 \%$ of the total species in reserve. It can be seen that although there were only 5 families in large family and larger family, the number of species in them accounted for $42.35 \%$ of the total species, closed to half of the total number of species, which were the dominant families in reserve. They were Gramineae, Compositae, Cyperaceae, Leguminosae and Polygonaceae.

Table 2. Statistics of family size of spermatophyte in Liangzi Lake Wetland Nature Reserve

\begin{tabular}{lccc}
\hline \multicolumn{1}{c}{ Item } & Family & Genus & Species \\
\hline Large family & 2 & 77 & 121 \\
Larger family & 3 & 32 & 92 \\
Medium family & 7 & 56 & 98 \\
Oligarchic family & 45 & 102 & 163 \\
Single family & 29 & 29 & 29 \\
Total & 86 & 296 & 503 \\
\hline
\end{tabular}

\subsection{Composition of genera}

There were 296 genera of spermatophyte in Liangzi Lake Wetland Nature Reserve, which were divided into four grades (Table 3): large genus (more than 10 species), medium genus (5-9 species), oligarchic genus (2-4 species) and single genus (1 species).

The results showed that there were only 3 genera in the large genus, accounting for $1.01 \%$ of the total genera in reserve. They were Polygonum, Artemisia and Cyperus. There were 13 genera in medium genus, accounting for $4.39 \%$ of the total genera in reserve, such as Fimbristylis, Carex, Scirpus, Veronica, Eleocharis, Euphorbia, Ranunculus, etc. There were 75 genera and 205 genera in oligarchic genus and single genus respectively. They contained 395 species, accounting for $78.53 \%$ of the total species, which was an important part of the genera in reserve and the reason for the diversity of the genera.

Table 3. Statistics of genera size of spermatophyte in Liangzi Lake Wetland Nature Reserve

\begin{tabular}{lcc}
\hline \multicolumn{1}{c}{ Item } & Genus & Species \\
\hline Large genus & 3 & 36 \\
Medium genus & 13 & 72 \\
Oligarchic genus & 75 & 190 \\
Single genus & 205 & 205 \\
Total & 296 & 503 \\
\hline
\end{tabular}

\subsection{Distribution types of families}

According to the distribution type system of the world spermatophyte family of Z. Y. Wu [5], 86 families in the reserve were divided into 7 distribution types and 4 variants (Table 4). They can be divided into 3 types: cosmopolitan (Type 1), tropical distribution (Type 2-7) and temperate distribution (Type 8-10).

Table 4. Statistics of distribution types of spermatophyte families in Liangzi Lake Wetland Nature Reserve

\begin{tabular}{|c|c|c|c|}
\hline $\begin{array}{l}\text { Type } \\
\text { code }\end{array}$ & Distribution types & $\begin{array}{l}\text { Numbers } \\
\text { of family }\end{array}$ & $\begin{array}{c}\text { Percentage } \\
(\%)\end{array}$ \\
\hline 1 & Cosmopolitan & 38 & 44.19 \\
\hline 2 & Pantropic & 26 & 30.23 \\
\hline $2-2$ & $\begin{array}{l}\text { Tropical Asia, Africa \& } \\
\text { South America disjuncted }\end{array}$ & 1 & 1.16 \\
\hline $2 \mathrm{~S}$ & $\begin{array}{l}\text { Tropical Asia, Africa \& } \\
\text { South America disjuncted }\end{array}$ & 3 & 3.49 \\
\hline 3 & $\begin{array}{l}\text { Tropical Asia \& Tropical } \\
\text { America disjuncted }\end{array}$ & 2 & 2.33 \\
\hline 4 & Old World Tropics & 1 & 1.16 \\
\hline $7 d$ & New Geainea & 1 & 1.16 \\
\hline 8 & North Temperate & 3 & 3.49 \\
\hline $8-4$ & $\begin{array}{l}\text { North Temperate \& South } \\
\text { Temperate disjuncted }\end{array}$ & 9 & 10.47 \\
\hline 9 & $\begin{array}{c}\text { East Asia \& North Ameira } \\
\text { disjuncted }\end{array}$ & 1 & 1.16 \\
\hline 10 & Old World Temperate & 1 & 1.16 \\
\hline Total & & 86 & 100.00 \\
\hline
\end{tabular}

\subsubsection{Cosmopolitan families}


There were 38 cosmopolitan families in Liangzi Lake Wetland Nature Reserve, accounting for $44.19 \%$ of the total families in reserve. Families with more species including: Gramineae, Compositae, Cyperaceae, Leguminosae, Polygonaceae, Scrophulariaceae, Labiatae, Rosaceae, Cruciferae, Umbelliferae, etc.

It can be seen that although the cosmopolitan families accounted for a large proportion in the total families of the reserve, they were not enough to reflect the characteristics of the flora of the reserve. Because the cosmopolitan families were distributed all over the world, they just play an important role in enriching the plant diversity of the reserve.

\subsubsection{Tropical distribution families}

There were 34 tropical distribution families in Liangzi Lake Wetland Nature Reserve, accounting for $39.53 \%$ of the total families. The distribution types with the most families were pantropical distribution family and its variants, which had 30 families, accounting for $34.88 \%$ of the total families in reserve. For example, Euphorbiaceae, Viticeae, Tetrandriaceae, Araceae, Sapindaceae, Cucurbitaceae, Malvaceae, Tiliaceae, etc.

The second was tropical Asia, Africa and South America disjuncted distribution family, which had 2 families, accounting for $2.33 \%$ of the total families in reserve, respectively Verbenaceae and Lardizabalaceae.

It can be seen that the main component of the tropical distribution family were the pantropic distribution family and its variants, and the tropical distribution family played a significant role in the whole flora.

\subsubsection{Temperate distribution families}

The temperate distribution families in Liangzi Lake Wetland Nature Reserve were 14 families, accounting for $16.28 \%$ of the total families. The distribution types with the most families were north temperate distribution family and its variant, which had 12 families, accounting for $13.95 \%$ of the total families in reserve. They were the main distribution types of temperate distribution families. For example, Liliaceae, Juncaceae, Fagaceae, Salicaceae, Caprifoliaceae, Juglandaceae, Papaveraceae, etc.

In addition, East Asia and North Ameira disjuncted distribution family and old world temperate distribution family each contained 1 family, each accounting for $2.33 \%$ of the total families in reserve. They were Saururaceae and Trapaceae respectively.

\subsection{Distribution types of genera}

According to the distribution types of spermatophyte genera in China of Z. Y. Wu [6], 296 genera in the reserve were divided into 14 distribution types and 9 variants (Table 5). They can be divided into 4 types: cosmopolitan (Type 1), tropical distribution (Type 2-7), temperate distribution (Type 8-14) and endemic to China distribution (Type 15).
Table 5. Statistics of distribution types of spermatophyte genera in Liangzi Lake Wetland Nature Reserve

\begin{tabular}{|c|c|c|c|}
\hline $\begin{array}{l}\text { Type } \\
\text { code }\end{array}$ & Distribution types & $\begin{array}{l}\text { Numbers } \\
\text { of genus }\end{array}$ & $\begin{array}{l}\text { Percentage } \\
\quad(\%)\end{array}$ \\
\hline 1 & Cosmopolitan & 58 & 19.59 \\
\hline 2 & Pantropic & 72 & 24.32 \\
\hline $2-1$ & $\begin{array}{c}\text { Tropical Asia, Australasia } \\
\text { \& South America } \\
\text { disjuncted }\end{array}$ & 2 & 0.68 \\
\hline $2-2$ & $\begin{array}{l}\text { Tropical Asia, Africa \& } \\
\text { South America disjuncted }\end{array}$ & 1 & 0.34 \\
\hline 3 & $\begin{array}{l}\text { Tropical Asia \& Tropical } \\
\text { America disjuncted }\end{array}$ & 5 & 1.69 \\
\hline 4 & Old World Tropics & 18 & 6.08 \\
\hline $4-1$ & $\begin{array}{c}\text { Tropical Asia, Africa and } \\
\text { Australasia }\end{array}$ & 2 & 0.68 \\
\hline 5 & $\begin{array}{c}\text { Tropical Asia to Tropical } \\
\text { Australasia }\end{array}$ & 6 & 2.03 \\
\hline 6 & $\begin{array}{c}\text { Tropical Asia to Tropical } \\
\text { Africa }\end{array}$ & 1 & 0.34 \\
\hline 7 & $\begin{array}{l}\text { Tropical Asia (Indo- } \\
\text { Malesia) }\end{array}$ & 9 & 3.04 \\
\hline $7 \mathrm{~d}$ & New Geainea & 1 & 0.34 \\
\hline 8 & North Temperate & 21 & 7.09 \\
\hline $8-4$ & $\begin{array}{l}\text { North Temperate \& South } \\
\text { Temperate disjuncted }\end{array}$ & 27 & 9.12 \\
\hline $8-5$ & $\begin{array}{c}\text { Eurasia \& Temperate South } \\
\text { America disjuncted }\end{array}$ & 3 & 1.01 \\
\hline 9 & $\begin{array}{c}\text { East Asia \& North Ameira } \\
\text { disjuncted }\end{array}$ & 12 & 4.05 \\
\hline 10 & Old World Temperate & 17 & 5.74 \\
\hline $10-1$ & $\begin{array}{l}\text { Mediterranea, West Asia } \\
\text { (or Central Asia) \& West } \\
\text { Asia disjuncted }\end{array}$ & 3 & 1.01 \\
\hline $10-3$ & $\begin{array}{l}\text { Eurasia \& South Africa } \\
\text { (sometimes also } \\
\text { Australasia) disjuncted }\end{array}$ & 6 & 2.03 \\
\hline 11 & Temperate Asia & 6 & 2.03 \\
\hline 12 & $\begin{array}{c}\text { Mediterranea, West Asia to } \\
\text { Central Asia }\end{array}$ & 1 & 0.34 \\
\hline 14 & East Asia & 11 & 3.72 \\
\hline $14 \mathrm{SJ}$ & Sino-Japan & 11 & 3.72 \\
\hline 15 & Endemic to China & 3 & 1.01 \\
\hline Total & & 296 & 100.00 \\
\hline
\end{tabular}

\subsubsection{Cosmopolitan genera}

There were 58 cosmopolitan genera in Liangzi Lake Wetland Nature Reserve, accounting for $19.59 \%$ of the total genera. Genus with 3 species and above including: Artemisia, Cyperus, Carex, Scirpus, Euphorbia, Ranunculus, Rumex, Viola, Rubus, Heleocharis, Juncus, Galium, Cardamine, Lysimachia, Bidens, Rorippa, Chenopodium, Solanum, Amaranthus, Physalis and Nymphoides.

\subsubsection{Tropical distribution genera}

There were 117 tropical distribution genera in Liangzi Lake Wetland Nature Reserve, accounting for $39.53 \%$ of the total genera. The distribution types with the most genera were pantropical distribution genus and its variants, which had 75 genera, accounting for $64.1 \%$ of the tropical distribution genera in reserve. Genus with 3 
species and above including: Rotala, Fimbristylis, Veronica, Echinochloa, Eragrostis, Phyllanthus, Smilax, Ipomoea, Kyllinga, Conyza, Ludwigia and Setaria.

The second was old world tropical distribution genus, which had 20 genera, accounting for $17.09 \%$ of the tropical distribution genera in reserve. They were Hemarthria, Achyranthes, Stephania, Themeda, Rostellularia, Hydrocharis, Grewia, Osbeckia, Arthraxon, Melia, Limnophila, Murdannia, Asparagus, Cayratia, Capillipedium, Striga, Mallotus, Monochoria, Gardenia and Rottboellia.

\subsubsection{Temperate distribution genera}

The temperate distribution genera in Liangzi Lake Wetland Nature Reserve were 121 genera, accounting for $40.88 \%$ of the total genera. The distribution types with the most genera were north temperate distribution genus and its variants, which had 51 genera, accounting for $42.15 \%$ of the temperate distribution genera in reserve. For example, Polygonum, Vicia, Potentilla, Oenanthe, Lonicera, Clinopodium, Cirsium, Vitis, Aster, Corydalis, etc.

The second was old world temperate distribution genus, which had 26 genera, accounting for $21.49 \%$ of the temperate distribution genera in reserve. For example, Trapa, Sonchus, Medicago, Torilis, Ajuga, Avena, Melilotus, etc.

\subsubsection{Endemic to China distribution genera}

There were 3 endemic to China distribution genera in Liangzi Lake Wetland Nature Reserve, accounting for $1.01 \%$ of the total genera. They were Koelreuteria, Poncirus and Indocalamus.

\section{Conclusion and discussion}

There were 503 species of spermatophyte in Liangzi Lake Wetland Nature Reserve belonging to 296 genera and 86 families. Five families were dominant in the reserve, which were Gramineae, Compositae, Cyperaceae, Leguminosae and Polygonaceae. The oligarchic and single genus contained 280 genera, which were the reason for the genera diversity. The Brasenia schreberi and Nelumbo nucifera in the reserve belong to the national first level protection. Glycine soja, Trapa incisa and Zelkova chneideriana belong to the national second level protection. In addition, Liangzi Lake Wetland Nature Reserve was the only habitat of Nymphaea stellata, which was a rare aquatic plant species in Asia.

The 86 families of spermatophyte can be divided into 7 distribution types and 4 variants. Tropic distribution type was dominant, accounting for $70.83 \%$ in total (excluding cosmopolitans). The proportion of tropical distribution family to temperate distribution family was about 2.4:1. In addition, the cosmopolitan families also reflects certain temperate attributes. The results showed that tropical components were dominant in this flora at family level.
The 296 genera of spermatophyte can be divided into 14 distribution types and 9 variants. Temperate elements were a little more than tropical elements, accounting for $50.84 \%$ and $49.16 \%$ in total (excluding cosmopolitans) respectively. In tropical distribution types, pantropic distribution genus and its variants were dominant. While in temperate distribution types, north temperate distribution genus and its variants were dominant. It can be seen that the transition between temperate and tropical elements was obvious.

In addition, the reserve contained 3 genera of the genus endemic to China, including 4 species. They were Koelreuteria paniculata, Koelreuteria bipinnata, Poncirus trifoliata and Indocalamus tesellatus, reflecting certain ancient relic.

Liangzi Lake Wetland Nature Reserve was rich in plant resources. It is suggested to regularly investigate the vegetation in the reserve, record its growth, file the data, establish a detailed database, and provide data support for the management and scientific research of the reserve [7]. Moreover, the protection measures for the reserve should be scientific and effective. We should take the endangered plants as the key protected objects, formulate clear protection measures, and reasonably develop and utilize the plant resources in the reserve. We need to increase efforts to publicize the ecological environment in the reserve and popularize the knowledge of ecological protection.

\section{Acknowledgments}

This research was financially supported by the Humanities and Social Science Research Program of Hubei Provincial Education Department (17G119 and 16G216), the Teaching Research Project of Hubei Provincial Universities (2017505) and the Scientific Research Project of Wuhan Institute of Design and Sciences (K201915).

\section{References}

1. H. Sun, T. Deng, Y.S.Chen, BS, 25, 2, 111-122 (2017)

2. C. Wang, Y.Zhu, L. L.Wang, EST, 38, S1, 398-404 (2015)

3. X. Y. Zhang, X. Y. Cai, E3S web of conferences (EDP Sciences, 79, 03010, 2019)

4. X. Y. Zhang, R. X. Liu, L. Y. Zhu, PSJ, 31, 5, 477484 (2013)

5. Z. Y. Wu, Z. K. Zhou, D. Z. Li, ABY, 25, 3, 245257 (2003)

6. Z. Y. Wu, H. Sun, Z. K. Zhou, Floristic geography of seed plants in China (Science Press, 2011)

7. L. Z. Chen, Flora and Vegetation Geography in China (Science Press, 2017) 